\title{
Point-of-Care Ultrasound Training for Family Medicine Residents: Examining the outcomes and feasibility of a pilot ultrasound curriculum
}

Gordon Yao, MD (ipr) BSc*; Taeyoung Peter Hong, MD CFPC*; Philip Lee, MD CFPC (EM); Joseph Newbigging, MD CCFP (EM); Brent Wolfrom, MD CCFP

Queen's University, Department of Medicine, Kingston, ON, Canada

*The first two authors should be considered as co-first authors for this paper.

\section{Introduction}

It is estimated that $50 \%$ of deaths due to abdominal aortic aneurysms (AAA) could be prevented by a national screening program $[1,2,3]$. Thanks to technological advancements and cost reductions, point-of-care ultrasound (POCUS) in family medicine (FM) is becoming more prevalent $[4,5]$. Despite the potential utility of POCUS in FM, of 224 FM residency programs surveyed, only $21 \%$ had developed a curriculum [6]. The main barriers identified to establishing a FM POCUS curriculum in Canadian FM residency programs were lack of trained faculty, lack of adequate equipment and lack of time in the curriculum [6].

Our study tested a pilot POCUS curriculum for first year
FM residents which was developed to improve competency in screening for AAA using POCUS. To address the barrier of many learners, and few trained faculty, we incorporated a "train-the-trainer" model. The first set of two residents were trained by Canadian POCUS (CPOCUS)-certified faculty members [7] during a week of evening clinics. These two residents subsequently trained the next subset of two residents, tumbling forward over four weeks until eight residents were trained. This minimized direct faculty teaching time.

The confidence, knowledge, and clinical competence of trainees were assessed at various time points to assess the efficacy of our curriculum.

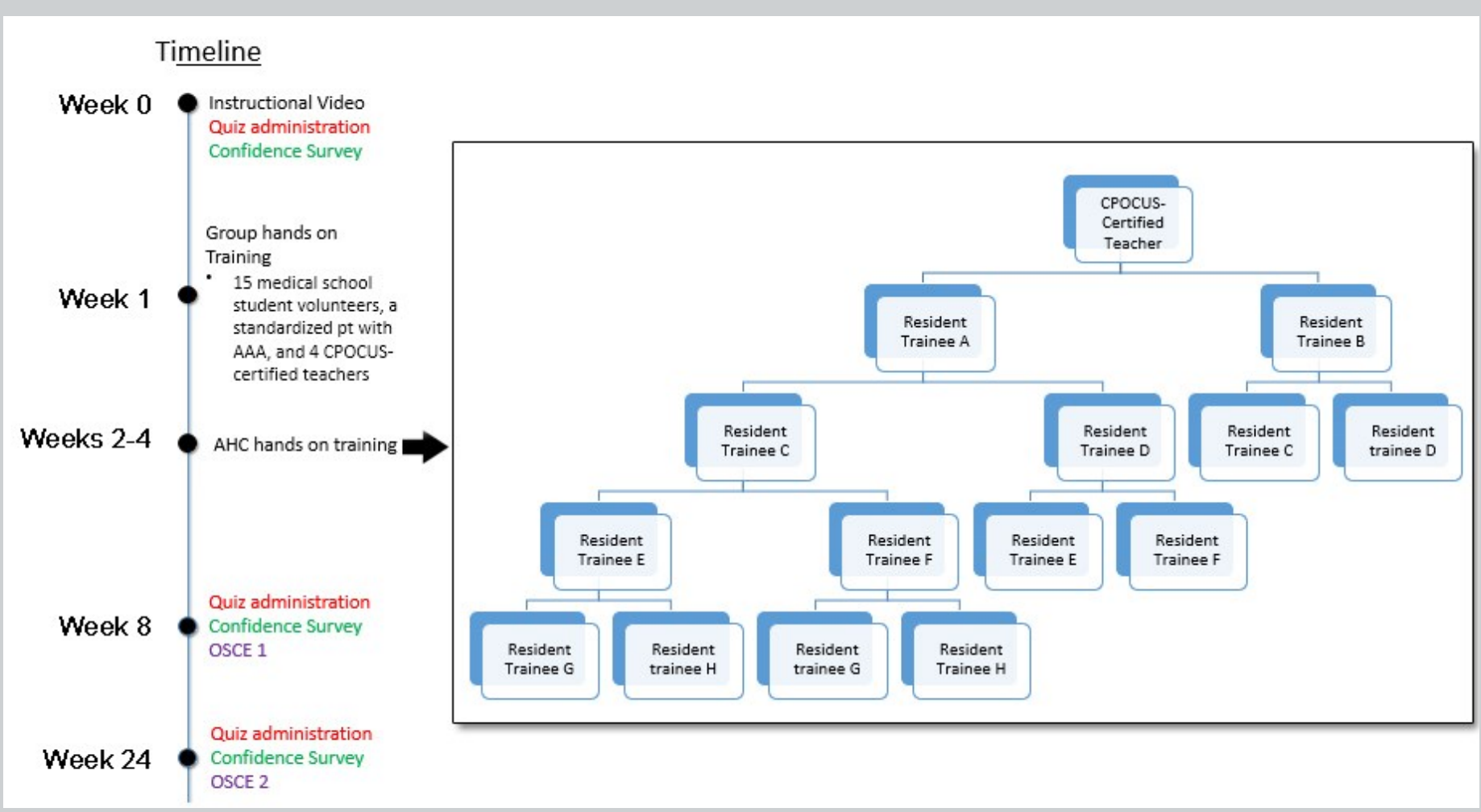

Figure 1. Pilot curriculum design with flow diagram depicting AHC rolling-forward structure of training and teaching. 
Table 1. Prior experience of residents with US

\begin{tabular}{|l|l|l|}
\hline Trainee & $\begin{array}{l}\text { Formal US training prior } \\
\text { to study }\end{array}$ & $\begin{array}{l}\text { Number of AAA } \\
\text { scans performed } \\
\text { prior to study }\end{array}$ \\
\hline 1 & $\begin{array}{l}\text { Basic/introductory ultra- } \\
\text { sound course (e.g. EDE1) }\end{array}$ & 4 \\
\hline 2 & $\begin{array}{l}\text { Obstetrical US training - } \\
\text { Biophysical profile, Esti- } \\
\text { mated fetal weight }\end{array}$ & 0 \\
\hline 3 & $\begin{array}{l}\text { Ultrasound training at } \\
\text { Queen's Family Clinic, } \\
\text { ultrasound workshop as a } \\
\text { medical student }\end{array}$ & 0 \\
\hline 4 to 8 & None & 0 \\
\hline
\end{tabular}

\section{Methods}

Approval was obtained from the Queen's University Research Ethics Board. Eight FM residents were recruited on a voluntary basis and surveyed to obtain demographic information and prior exposure to POCUS (Table 1).

One week prior to hands-on training, trainees were given access to a 30-minute video teaching basic knobology and physics, POCUS techniques, and clinical integration related to AAA. Subsequently, they were quizzed on this information to assess knowledge and confidence. Confidence was rated on a 5-point Likert scale $(1=$ "Not confident at all", 5 = "Fully confident").

The first hands-on session was taught by four CPOCUS- certified faculty [7] and senior Emergency Medicine (EM) residents. Trainees practiced on fifteen medical student volunteers and one standardized patient (SP) with an AAA. All trainees obtained sixteen supervised scans during this session.

Further training took place in an after-hours walk-in-clinic $(\mathrm{AHC})$ where patients were invited to volunteer to be scanned. Trainees were paired; Group 1 (trainees A and B) was trained by a POCUS certified instructor for 6 hours. Trainees A and B from Group 1 then trained Group 2 (trainees $C$ and D) for 3 hours each. Group 2 then trained Group 3 and so forth. Using this rolling-forward structure, each trainee received 6 hours of training and provided 3 hours of teaching.

Trainees were assessed for competency using an objective structured clinical examination (OSCE) tool which targeted patient preparation, image acquisition/ optimization, image interpretation, and clinical integration. Knowledge and confidence were assessed in the same domains using an electronic quiz and confidence survey. The same quiz was administered multiple times, but the answers were never provided.

For the OSCEs, two SPs (one with an AAA) were recruited. CPOCUS certified examiners blinded to the $\mathrm{AHC}$ training sessions scored trainees using an OSCE rubric created by the Queen's Department of Emergency Medicine (Table 2).

The quiz, confidence survey, and OSCE were administered once all residents completed AHC training, as well as four months later to assess retention. The quiz and confidence survey were also administered after trainees

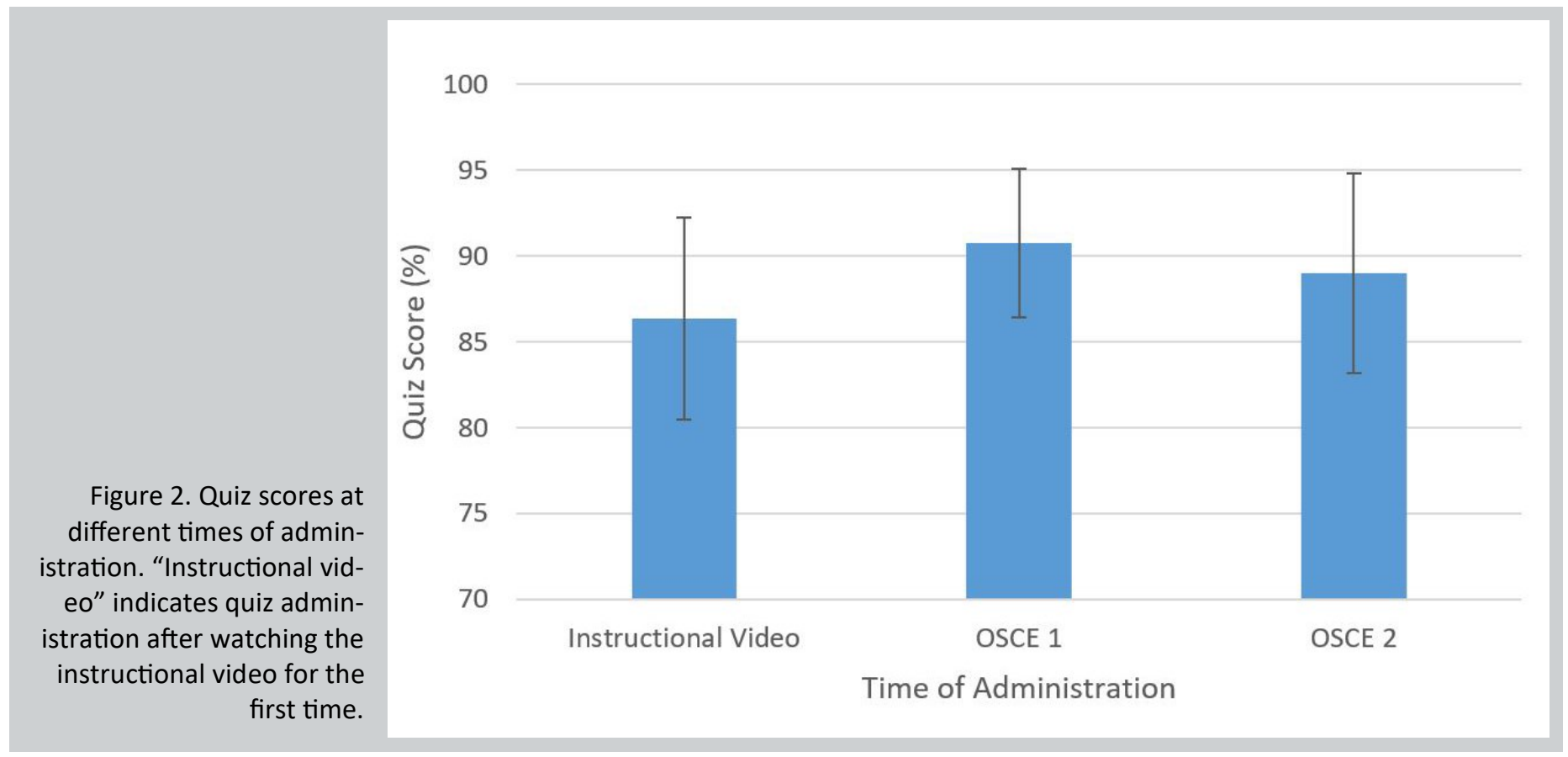


Table 2. OSCE Rubric with description of scores.

\begin{tabular}{|c|c|}
\hline Domain & Criteria assessed \\
\hline Preparation & $\begin{array}{l}\text { - Ergonomics (bed height, arm reach, } \\
\text { etc.) } \\
\text { - Patient position } \\
\text { - Probe Selection } \\
\text { - Gel application } \\
\text { - Draping } \\
\text { - Initial settings (depth, preset) } \\
\text { - Patient engagement }\end{array}$ \\
\hline $\begin{array}{l}\text { Image } \\
\text { Acquisition }\end{array}$ & $\begin{array}{l}\text { - Starting location } \\
\text { - Hand and probe position } \\
\text { - Identify appropriate landmarks } \\
\text { - Aorta discriminators } \\
\text { - Timing and economy of movement } \\
\text { - Measurement }\end{array}$ \\
\hline $\begin{array}{l}\text { Image } \\
\text { Optimization }\end{array}$ & $\begin{array}{l}\text { - Centers area of interest } \\
\text { - Appropriate gain } \\
\text { - Frequency adjustment } \\
\text { - Focal zone } \\
\text { - Troubleshooting (gas, umbilicus, fat, } \\
\text { artifacts) }\end{array}$ \\
\hline $\begin{array}{l}\text { Clinical } \\
\text { Integration }\end{array}$ & $\begin{array}{l}\text { - Interpretation (indeterminate, AAA, nor- } \\
\text { mal) } \\
\text { - Understands limitations of US scan } \\
\text { - Management priorities }\end{array}$ \\
\hline Score & Description \\
\hline 1 & $\begin{array}{l}\text { Inferior - delayed or incomplete perfor- } \\
\text { mance of all criteria. } \\
\text { Entrustment decision: observation only, no } \\
\text { execution }\end{array}$ \\
\hline 2 & $\begin{array}{l}\text { Novice - delayed or incomplete perfor- } \\
\text { mance of many criteria. } \\
\text { Entrustment decision: direct supervision } \\
\text { required }\end{array}$ \\
\hline 3 & $\begin{array}{l}\text { Competent - delayed or incomplete perfor- } \\
\text { mance of some criteria. } \\
\text { Entrustment decision: indirect supervision } \\
\text { required }\end{array}$ \\
\hline 4 & $\begin{array}{l}\text { Advanced - competent performance of } \\
\text { most criteria. } \\
\text { Entrustment decision: independent perfor- } \\
\text { mance with remote supervision }\end{array}$ \\
\hline 5 & $\begin{array}{l}\text { Superior - efficient and rapid performance } \\
\text { of all criteria. } \\
\text { Entrustment decision: supervision of train- } \\
\text { ees }\end{array}$ \\
\hline
\end{tabular}

had watched the training video but before hands-on training. Formative group feedback was provided after the first OSCE. However, answers were never provided for the quiz or questions posed during OSCES.

For quiz and confidence scores, single factor ANOVA was applied to the data to screen for significant differences in scores after watching the Instructional video and when OSCE 1 and 2 were administered. If $F>$ Fcrit, paired t-tests were applied to identify where significant differences were present (i.e. between instructional video and OSCE 1, between instructional video and OSCE 2 and/or between OSCE 1 and OSCE 2). Paired t-tests were utilized to assess whether significant differences $(p<0.05)$ were found in competency scores between OSCE 1 and OSCE 2. The same test was used to assess for significant differences between Group 1 vs. Group 4 OSCE scores. A summary of the study design is provided in Figure 1.

\section{Results}

Knowledge: quiz scores were $86.3 \%, 90.8 \%$ and $89.0 \%$ at Instructional video (i.e. after watching the video with no hands-on training), OSCE 1 and OSCE 2 respectively. There were no significant differences between scores (Figure 2).

Confidence: Between Instructional video and OSCE 1, all domains showed significant increase in confidence. Overall confidence after watching the instructional video averaged a score of 1.75 , increasing to 4.50 by OSCE 1 and remaining high at 4.33 by OSCE 2 . There was no significant difference in confidence in all domains between the two OSCEs (Figure 3).

Competency: There was no significant difference in OSCE scores between the two OSCEs, suggesting competency was retained after training for a minimum of four months. In both OSCEs, all trainees except for one had an entrustment decision score of 4 , which meant independent performance with remote supervision. One trainee in both OSCEs scored a 3 for entrustment decision, which meant indirect supervision was required; however, this was not the same trainee for both OSCEs, and the two individuals were only rated a 3 by one of two POCUS evaluators. All residents reported performing POCUS less than once a month between OSCEs 1 and 2. The average score of all the domains were 3.75 and 3.70 for OSCE 1 and 2, respectively (Figure 4).

Effect of rolling-forward AHC training: OSCE scores for Group 1 (trainees $A$ and $B$ ) in the $A H C$ were not significantly different from OSCE scores for Group 4 (trainees $\mathrm{G}$ and $\mathrm{H}$ ) in all competency domains (Figure 5). 


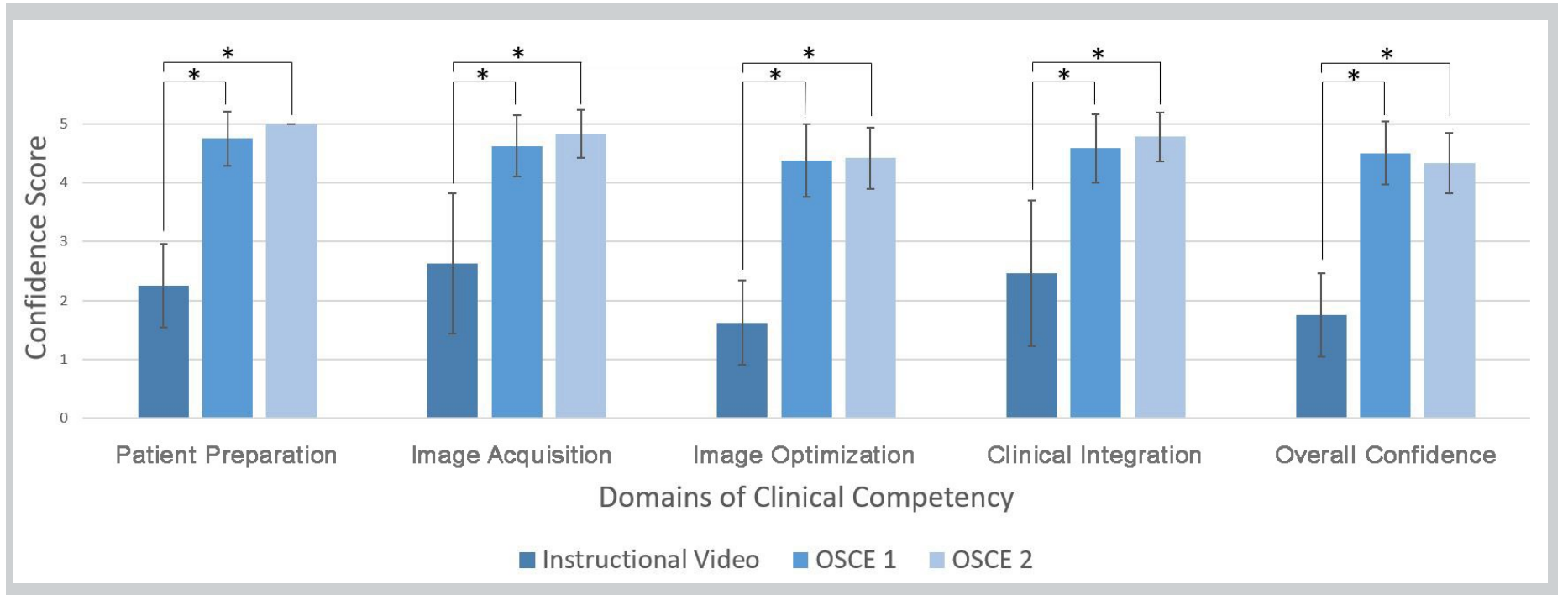

Figure 3. Confidence scores in each domain of clinical competency. Responses were gauged on a Likert scale where $1=$ "Not confident at all" and $5=$ "Fully confident." * $p<0.05$.

\section{Conclusion}

As part of the curriculum at Queen's university, FM residents participate in short horizontal experiences, each being an 8-16 hour commitment. The pilot POCUS curriculum had the same time commitment (total 12.5 hours) and ensured confidence, knowledge, and clinical competence that was retained at four months posttraining. Our study had a small sample size, but most of our trainees had no prior US training, which is common amongst other first year FM residents.

The rolling-forward "train-the-trainer" curriculum encouraged professionalism and minimized demands on faculty to provide hands on training. There were no apparent differences in confidence, knowledge, or competency for trainees who were taught by faculty compared to trainees taught by other trainees.

During both OSCEs, the CPOCUS-certified examiner directly observed residents measure the aorta and assessed them using an established rubric in order to assess competence. However, one limitation is that the quantitative accuracy of the actual AAA measurements performed by the learner during training was not directly assessed by the instructor. This could have been achieved by comparing the trainee's measurements with a CPOCUS-certified trainer's findings on the same abdominal aorta. Accuracy is important because: 1) false negative measurements would mean that prevention of a life-threatening condition ( $A A A=$ related mortality, rupture and emergency repair) could have been avoided, and 2) false positive measurements generate unnecessary confirmatory imaging, follow-up care including emergency transfer and specialist referrals, and undue patient stress. Blois (2012) did demonstrate that a family physician could develop an accuracy with less than $0.2 \mathrm{~mm}$ discrepancy from official measurements but the physician in this study received significantly more training (i.e. 50 supervised scans) [1].
Figure 4. OSCE scores for each domain of clinical competency. Scores were gauged on a Likert scale where 1 = "Observation only, no execution", 2 = "Direct supervision required", 3 = "Indirect supervision required", 4 = "Independent performance with remote supervision", 5 = "Supervision of trainees."

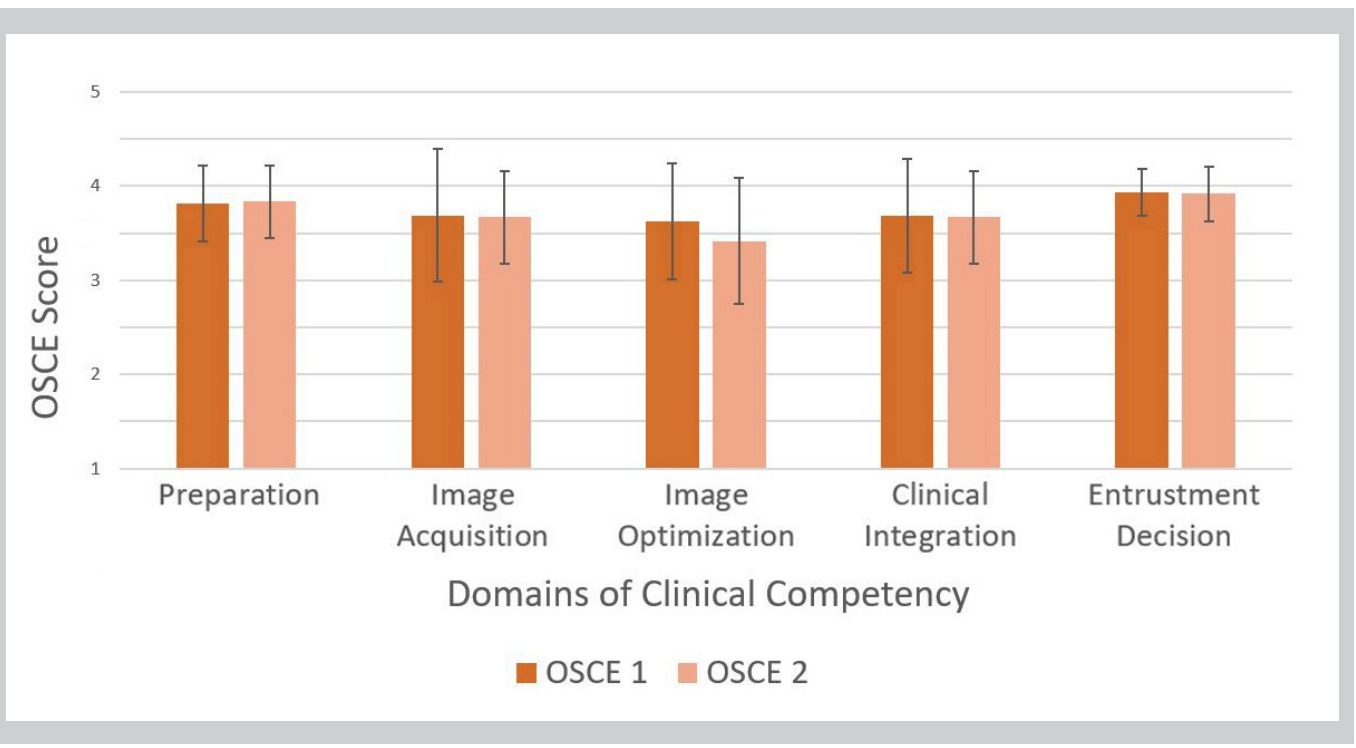


Figure 5. OSCE scores for each domain of clinical competency between

Group 1 (Trainee A and B) and Group 4 (Trainee $\mathrm{G}$ and $\mathrm{H}$ ) in rolling-forward

AHC training.

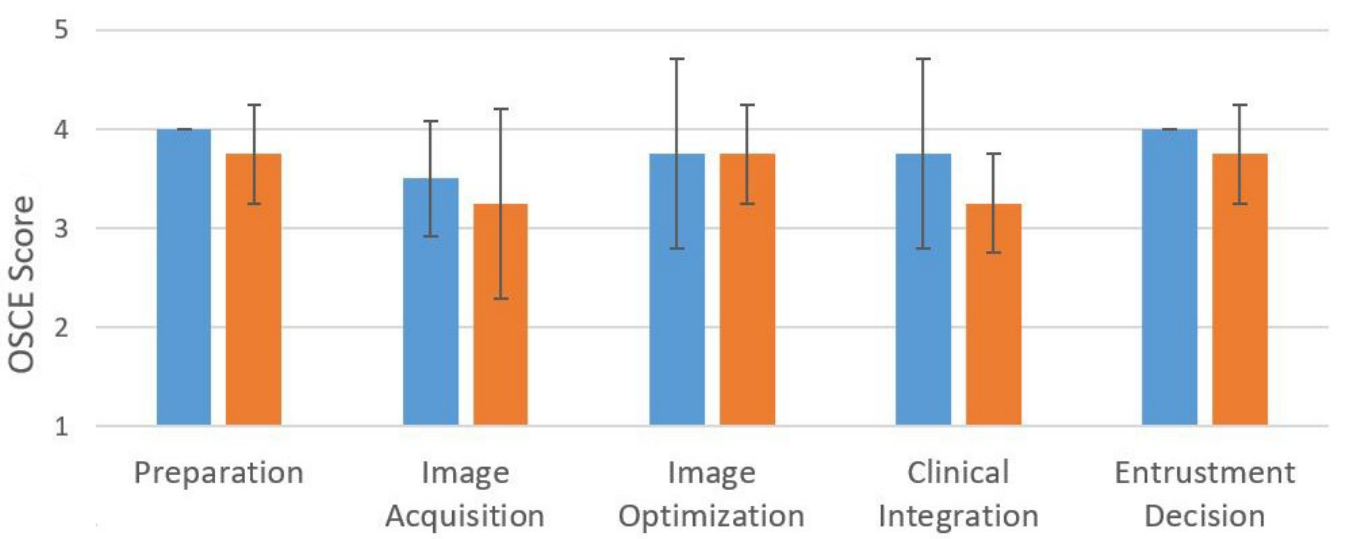

Domains of Clinical Competency

Group 1 Group 4
In 2016, Wilkinson et al. also studied the effectiveness of a condensed POCUS curriculum but for the purposes of teaching cardiac scans [8]. Trainees were required to diagnose several pathologies, such as severe left ventricular dysfunction and ventricular septal defects. Of note, the curriculum was short and only provided 4 hours of either hands-on-training or simulation-based training taught by senior residents or ultrasound technicians [8]. This study raised a legitimate concern that condensed curriculums may have the undesired effect of increasing trainee confidence without the necessary increase in competency. Despite a significant increase in trainee confidence, there was an increase in the false positive rate after the training [8].

In contrast to these findings, our trainees exhibited concomitant increases in confidence, knowledge, and clinical competency. This was likely because our curriculum taught a single application, was longer in duration (12.5 hours), and utilized several different teaching modalities including a didactic online lecture, hands-on practice taught by POCUS-trained physicians, and peer-to-peer training. In incorporating POCUS training into an already overflowing medical curriculum, it is vital that the POCUS curriculums developed not only increase trainee confidence but also ensure clinical competency and improve patient care.

For FM residents interested in incorporating POCUS into their future practice, studying the efficacy of this teaching curriculum when applied to an entire FM residency program should be considered. The supplemental curriculum we have developed has the potential to teach them a lifesaving scan which would be indicated for many patients seen in a typical FM practice [1, 2].

\section{References}

1. Blois B. Office-based ultrasound screening for abdominal aortic aneurysm. Can Fam Physician 2012; 58(3): e172-8.

2. Bailey RP, Ault M, Greengold NL, et al. Ultrasonography performed by primary care residents for abdominal aortic aneurysm screening. $\mathrm{J}$ Gen Intern Med 2001; 16(12):845-849.

3. Abdominal Aortic Aneurysm [Internet]. Canadian Task Force 2017 [cited 2018 Oct 20]. Available from: https://canadiantaskforce.cal guidelines/published-guidelines/abdominal-aortic-aneurysm/.

4. Moore CL, Copel JA. Point-of-care Ultrasonography. N Engl J Med 2011; 364(8):749-757.

5. Wordsworth S, Scott A. Ultrasound scanning by general practitioners: is it worthwhile? J Public Health Med 2002; 24(2): 88-94.

6. Canadian national survey of point-of-care ultrasound training in family medicine residency programs. Can Fam Physician. 2018; 64(10): e462e467.

7. Canadian Point of Care Ultrasound Society [Internet]. Available from www.cpocus.ca.

8.Wilkinson JS, Barake W, Smith C, Thakrar A, Johri A. Limitations of Condensed Teaching Strategies to Develop Hand-Held Cardiac Ultrasonography Skills in Internal Medicine Residents. CJC 2016; 32(8): 10341037. 